\title{
Pulmonary Embolism in Patients Hospitalized for Exacerbated COPD and Wheezing
}

Claire Poulet ${ }^{1}$, Marine Woimant ${ }^{1}$, Estelle Hoguet ${ }^{1}$, Éline Magois ${ }^{1}$, Marianne Auquier ${ }^{2}$, Marie-Antoinette Sevestre-Pietri ${ }^{3}$, Damien Basille ${ }^{1}$, Claire Andréjak ${ }^{1}$ and Vincent Jounieaux ${ }^{1^{\star}}$

${ }^{1}$ Respiratory Intensive Care Unit and Pneumology Unit, Centre Hospitalier Universitaire, 80054 AMIENS Cedex 1, France

${ }^{2}$ Radiology Unit, Centre Hospitalier Universitaire, Amiens, France

${ }^{3}$ Vascular Medicine Unit, Centre Hospitalier Universitaire, Amiens, France

\begin{abstract}
Background: Prevalence of pulmonary embolism (PE), a potentially lethal disease which can mimic exacerbation of chronic obstructive pulmonary disease (COPD) remains controversial.
\end{abstract}

Objective of the study: The main objective was to determine prevalence of PE in COPD patients hospitalized for exacerbation with wheezing at presentation. The secondary objectives were to compare the prevalence of PE according to COPD GOLD stages and to identify predictive factors for PE in COPD population.

Methods: We conducted a prospective study in all consecutive patients hospitalized for COPD exacerbation of unknown origin with wheezing at presentation. Patients underwent a spiral computed tomography (CT) angiography and venous lower-limb Doppler ultrasonography.

Results: 87 patients $(71$ males, mean age: $67.1 \pm 11.2$ years, 32 GOLD stage-III and 24 GOLD stage-IV patients) had an interpretable spiral CT angiography which showed eight right and five bilateral unsuspected PEs. Deep vein thrombosis was found in nine patients (associated with PE in three). The prevalence of PE and venous thromboembolism (VTE) occurred respectively in $14.9 \%$ and $21.8 \%$. No statistical differences were found between risk factors, Geneva score or clinical signs in patients with and without PE. PE was not related to the severity of COPD.

Conclusion: There was a $14.9 \%$ prevalence of unexpected PE in patients with exacerbated COPD and wheezing at presentation. VTE events were not correlated with the severity of COPD.

Keywords: Pulmonary embolism; COPD; Intensive care unit; Emergencies; Wheezing

\section{Introduction}

Nearly $30 \%$ of exacerbated chronic obstructive pulmonary disease (COPD) have no clear aetiology [1]. In this subgroup of patients admitted for COPD exacerbation, available information on the prevalence of pulmonary embolism (PE) remains scarce and conflicting with data ranging from $0 \%$ [2] to $29 \%$ [3]. Because PE remains a potentially lethal disease with clinical symptoms that can mimic exacerbated COPD (increased dyspnoea, tachycardia, hypoxemia and/ or right-sided heart failure) and because Wells and/or Geneva scores are (usually) intermediate in exacerbated COPD patients, this issue is of great importance.

Thus, clinicians need tools to cope with the risk of undiagnosed PE in such COPD patients. In our experience, when exacerbated COPD is accompanied by wheezing at auscultation, the spectra of PE becomes substantial [3]. When present, this clinical symptom which is not systematically found in exacerbated COPD could focus clinicians' attention on the possibility of unsuspected PE [4]. To confirm this hypothesis, we conducted a prospective study to assess the prevalence of PE in a selected large population of COPD patients requiring hospitalization for a bronchospastic exacerbation. We also hypothesized that the more severe the COPD, the higher should be the prevalence of PE according to the features of these patients (inactivity, right-sided heart failure, polycythemia and/or advanced age) and thus looked for relationships between PE and GOLD stage.

\section{Materials and Methods}

\section{Study group}

From September 2007 to March 2011, all patients hospitalized for severe exacerbation of COPD of unknown origin with wheezing at presentation were checked for venous thromboembolism (VTE). Patients were proposed for spiral computed tomography (CT) angiography and venous lower-limb colour Doppler ultrasonography if their Geneva and Wells probability clinical scores [5] were high or if they were low or intermediate with a positive D-Dimers blood test [6].

COPD was diagnosed before or during hospitalization on the basis of tobacco exposure, clinical symptoms and pulmonary function tests. CT scans were performed to detect unsuspected PE but not used to assess COPD diagnosis. COPD severity was determined according to the criteria of the American Thoracic Society (2006 GOLD score) $[7,8]$. Severe exacerbation requiring hospitalization was defined as acute COPD deterioration with persistent respiratory clinical symptoms despite repeated bronchodilatators nebulisations delivered in the emergency room or as acute COPD deterioration with severity criteria (respiratory frequency $>30 / \mathrm{min}$, heart rate $>120 / \mathrm{min}$, cyanosis, systolic arterial pressure $<90 \mathrm{mmHg}, \mathrm{SpO}_{2}<90 \%$ and/or $\mathrm{pH}<7.35$ ).

We excluded COPD patients with an obvious cause of exacerbation (myocardial infarction, pneumothorax, pneumonia...) and those with a contraindication for spiral CT angiography, such as a creatinine clearance $<30 \mathrm{~mL} / \mathrm{min}$ or an allergy to intravenous contrast medium.

${ }^{*}$ Corresponding author: Vincent Jounieaux, Respiratory Intensive Care Unit and Pneumology Unit, Centre Hospitalier Universitaire, 80054 AMIENS Cedex 1, France, E-mail: jounieaux.vincent@chu-amiens.fr

Received March 24, 2015; Accepted May 25, 2015; Published May 29, 2015

Citation: Poulet C, Woimant M, Hoguet E, Magois É, Auquier M, et al. (2015) Pulmonary Embolism in Patients Hospitalized for Exacerbated COPD and Wheezing. J Pulm Respir Med 5: 264. doi:10.4172/2161-105X.1000264

Copyright: $\odot 2015$ Poulet $C$, et al. This is an open-access article distributed under the terms of the Creative Commons Attribution License, which permits unrestricted use, distribution, and reproduction in any medium, provided the original author and source are credited. 
We excluded patients with a non-interpretable spiral CT angiography.

We also excluded from the study patients with a non-high clinical probability of $\mathrm{PE}$ and a negative $\mathrm{D}$-dimers blood test because these patients did not undergone spiral CT angiography leading to the impossibility to excluded completely EP in this subgroup of patients.

Patients were hospitalized in intensive care unit (ICU) in case of haemodynamic instability (systolic arterial pressure $[\mathrm{SAP}]<90 \mathrm{mmHg}$ ), hypoxemia requiring high concentration of oxygen or mechanical ventilation and/or respiratory acidosis $(\mathrm{pH}<7.35)$. The study was run for 6 months for all patients.

This study received approval from the Ethics Committee (CPP Nord-Ouest II, No. 2007/18, Direction Générale de la Santé, No. DGS2007- 0345). All patients gave written informed consent for their participation in the study.

\section{Materials}

D-Dimers were considered positive if their values were $\geq 500 \mathrm{ng} /$ $\mathrm{mL}$ (D-Dimer Liatest ELISA assay). Spiral CT angiography were done within $48 \mathrm{~h}$ of admission, using a general electric VCT scanner (64 slices) with the following protocol: acquisition by helical mode collimation of $0.6 \mathrm{~mm}$ that covered the entire thorax, injection of non-ionic contrast iodine (320 $\mathrm{mg}$ ) through a venous 18 - or 20-gauge catheter inserted in an antecubital vein, use of a syringe for double biphasic injection of 60 $\mathrm{ml}$ of product contrast at $4 \mathrm{ml} / \mathrm{s}$, followed by a bolus of $30 \mathrm{ml}$ of saline solution at $4 \mathrm{ml} / \mathrm{s}$. Smart Prep Software (General Electric) was used to automatically detect the arrival of contrast bolus in real-time using predetermined areas (right atrium to pulmonary arteries). The spiral CT angiography data were immediately interpreted by a radiologist and checked afterwards by another radiologist who was a referent in thoracic imaging and not informed of the initial interpretation. In case of discrepancies between the two interpretations, a third one was carried out by a third radiologist. The spiral CT angiography data were always analysed independently from clinical data which were captured before CT.

Ultrasonographic criteria for deep-vein thrombosis were noncompressibility or incomplete compressibility of the vein. Patients underwent a 6-min walk test and functional respiratory tests at the end of hospitalization and 3 months later.

\section{Statistical analyses}

We determined that 89 COPD patients with bronchospastic exacerbation needed to be included in our study to determine the prevalence of $\mathrm{PE}$ in this population with an a risk of 5\%. This value was calculated from the prevalence $(6.2 \%)$ reported in the study of Rutschmann et al. (this study including the largest population of exacerbated COPD patients) [9]. PE frequency was expressed as a percentage. We did comparative analysis, according to PE diagnosis or not, using Fisher's exact test for qualitative variables and Student's t-test or the Kruskal-Wallis nonparametric test according to the distribution of variables. An univariate survival analysis was done with a Kaplan Meier curve. A level of $p=0.05$ was considered statistically significant. SAS 9.2 software was used for the analysis.

\section{Results}

Between september 2007 and march 2011,97 patients were admitted to our hospital (Centre Hospitalier Universitaire, Amiens, France) for acute COPD exacerbation with wheezing at presentation. Among these patients, five did not achieve the inclusion criteria: two because low or intermediate clinical scores with negative D-Dimers, one because chronic renal failure, one patient because obvious signs of pneumonia $24 \mathrm{~h}$ after admission and the last one because lacked spirometric data. Another five patients were excluded from the study because of noninterpretable spiral CT angiography: one had a deep-vein thrombosis at presentation and was treated with anticoagulation treatment whereas the remaining four did not receive any anticoagulant treatment with no pulmonary embolism and/or deep-vein thrombosis events during the 6 months follow-up.

The remaining eighty seven patients were included in the study (71 males, mean age: $67.1 \pm 11.2$ years). Thirty eight patients $(43.7 \%)$ had risk factors for PE : cancer $(n=13,14.9 \%)$, previous venous thromboembolism (VTE : deep-vein thrombosis and/or PE) $(n=10$, $11.5 \%)$, venous insufficiency $(n=10,11.5 \%)$, obesity (BMI $\geq 25 \mathrm{~kg} /$ $\left.\mathrm{m}^{2}, n=11,12.6 \%\right)$, recent surgery $(n=10,11.5 \%)$, bone fracture $(n=2$, $2.3 \%)$, central venous catheter $(n=2,2.3 \%)$ or known thrombophilia $(n=1)$. The most frequent underlying disease, after exclusion of $\mathrm{PE}$ risk factors, was chronic heart failure $(n=8,9.2 \%)$. COPD was severe (32 GOLD stage-III patients and 24 GOLD stage-IV patients) with, on average, a forced expiratory volume in $1 \mathrm{~s}\left(\mathrm{FEV}_{1}\right)$ of only $42.5 \pm$ $16.9 \%$ of normal predicted values. No patients were hospitalized the month preceding their COPD exacerbation. No female patients were undergoing menopausal hormone treatment.

At admission, all patients were bronchospastic (inclusion criteria) whereas an increased cough was observed only in 53 patients $(60.9 \%)$, an increased sputum volume in $53(60.9 \%)$, a chest pain in $11(12.6 \%)$ and haemoptysis in 2 (2.3\%). Proportions of patients with low, intermediate and high clinical probability of PE were respectively for the Geneva score: $14.9 \%, 73.6 \%, 11.5 \%$, and for the Wells score: $43.7 \%$, $52.9 \%, 3.4 \%$. Mean Geneva and Wells scores were respectively: $4.8 \pm 1.7$ and $4.5 \pm 1.3$.

Among these 87 patients, 41 (47.1\%) were admitted into the ICU (Figure 1). The biological data (at admission) for the group as a whole are presented in Table 1.

Spiral CT angiography was performed in all 87 patients (inclusion criteria). Spiral CT angiography interpretations were consistent between the two blinded radiologists in 79 cases but required a supplemental interpretation by a third radiologist in eight cases due to discordant results. Finally, among the 87 patients, spiral CT angiography showed thirteen unsuspected PEs, eight right PEs and five bilateral PEs. PEs were proximal in 3 patients, segmental in 4 patients and subsegmental in the remaining 6 patients. Eighty four patients underwent lower-limb compression ultrasonography of proximal veins which showed a deep vein thrombosis in 9 patients (associated with PE in 3 patients).

According these results, the prevalence of unsuspected PE was $14.9 \%$ and the prevalence of unsuspected VTE (pulmonary embolism and/or deep-vein thrombosis) was $21.8 \%$. No statistical difference were found between COPD patients with and without PE (or VTE) according to risk factors, Geneva score or clinical signs (Table 2) whereas the Wells score appeared significantly higher in COPD patients with PE than without $\mathrm{PE}$ (respectively, $5.2 \pm 1.2$ vs. $4.4 \pm 1.3 ; p=0.014$ ). Cough was found less frequently in patients with $\mathrm{PE}$ compared to patients without PE.

PE was not related to the severity of COPD and occurred in $16.7 \%$ GOLD stage-I and -II patients, 25.9\% GOLD stage-III patients and $9.1 \%$ in GOLD stage-IV patients $(p=0.34)$. Despite no significant statistical differences, unsuspected PE seemed marginally more frequent in patients admitted into ICU when compared to patients admitted into standard pneumology ward (respectively: $20.5 \%$ vs. $9.8 \% ; p=0.143$ ). 


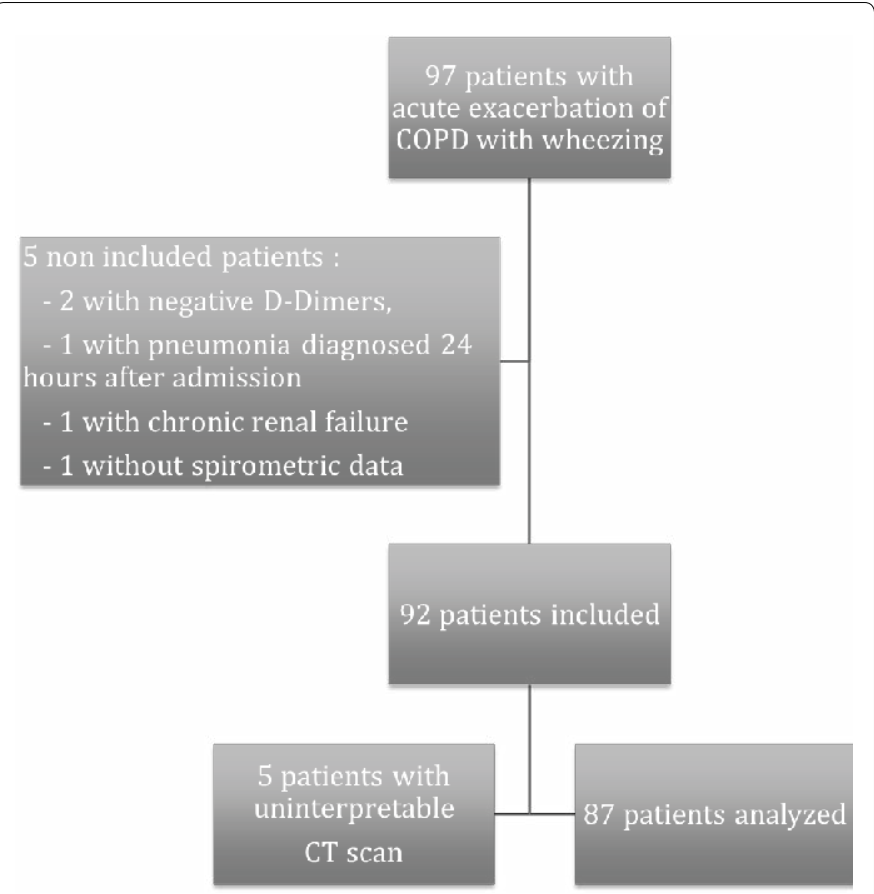

Figure 1: Flow-chart of the study.

\begin{tabular}{|l|l|l|}
\hline & Mean \pm standard deviation & Median [range] \\
\hline $\mathrm{PaO}_{2} / \mathrm{FiO}_{2}$ ratio & $246.0 \pm 79.1$ & $242.9[70-467]$ \\
\hline $\mathrm{PaCO}_{2}(\mathrm{mmHg})$ & $53.4 \pm 19.5$ & $47[26-108]$ \\
\hline $\mathrm{pH}$ & $7.35 \pm 0.09$ & $7.36[7.14-7.80]$ \\
\hline Lactate $(\mathrm{mmol} / \mathrm{L})$ & $1.82 \pm 0.94$ & $1.70[0.6-6.9]$ \\
\hline $\mathrm{BNP}(\mathrm{ng} / \mathrm{L})$ & $349.48 \pm 453.94$ & $166.50[16-2400]$ \\
\hline CRP $(\mathrm{mgL})$ & $69.45 \pm 78.03$ & $32[3-366]$ \\
\hline Troponin $(\mathrm{ng} / \mathrm{mL})$ & $0.15 \pm 0.51$ & $0.03[0.0-4.1]$ \\
\hline D Dimers $((\mu \mathrm{g} / \mathrm{mL})$ & $1.61 \pm 1.04$ & $1.19[0.52-4]$ \\
\hline
\end{tabular}

Table 1: Biological data at admission for the whole population

D-Dimers values were found higher in patients with $\mathrm{PE}$ than without PE (respectively: $2.24 \pm 1.16$ vs. $1.50 \pm 0.98 \mu \mathrm{g} / \mathrm{mL} ; p=0.023$ ). $\mathrm{PCO}_{2}$ values were similar between patients with and without PE (respectively, $46.7 \pm 14.5$ vs. $53.5 \pm 21.6 \mathrm{mmHg}, p=0.280$ ) (Table 2).

Only one adverse event was notified during the study corresponding to a patient who developed after the spiral CT angiography an acute on chronic renal failure (previous creatinine clearance of $52 \mathrm{~mL} / \mathrm{min}$ ). Nevertheless, his renal function improved after fluid expansion and previous renal function was recovered. Six patients with a PE died during the follow-up. The median survival time of patients with $\mathrm{PE}$ was 34 months (CI95\%: 22-46) versus 61 months (CI95\%: 43-79) for patients without PE (log rank, $p=0.1$; Figure 2) According to the site of PE, no death was observed in the subgroup "proximal", 3 in the subgroup "segmental" and 3 in the subgroup "sub-segmental". No statistical analysis could be done on these too small data.

\section{Discussion}

This prospective monocentric study found a $14.9 \%$ prevalence of pulmonary embolism (PE) and a $21.8 \%$ prevalence of venous thromboembolic disease (VTE) in patients hospitalized for exacerbated COPD with wheezing at presentation. Moreover, these unexpected PE or VTE events were not correlated with the of COPD severity.

\begin{tabular}{|c|c|c|c|}
\hline & $\begin{array}{l}\text { Non PE group } \\
(n=74)\end{array}$ & PE group $(n=13)$ & p \\
\hline Age, mean \pm SD & $66.5 \pm 11.10$ & $70.77 \pm 12.33$ & 0.212 \\
\hline PE risk factors, $\mathrm{n}(\%)$ & $31(41.9 \%)$ & $7(53.8)$ & 0.307 \\
\hline Cancer history, n (\%) & $10(13.5)$ & $3(23.1)$ & 0.3 \\
\hline GOLD III and IV, n (\%) & $47(64.4 \%)$ & $9(69.2 \%)$ & 0.552 \\
\hline FEV1 ( $\%$ pred), mean \pm SD & $41.6 \pm 17.1$ & $47.1 \pm 15.9$ & 0.28 \\
\hline Intensive care unit, $\mathrm{n}(\%)$ & $35(48.6 \%)$ & $9(69.2 \%)$ & 0.143 \\
\hline Wells score, mean \pm SD & $4.42 \pm 1.29$ & $5.23 \pm 1.23$ & 0.04 \\
\hline $\begin{array}{l}\text { Wells score higher than } 5, \mathrm{n} \\
(\%)\end{array}$ & $14(18.9)$ & $6(46.2)$ & 0.04 \\
\hline Geneve score, mean \pm SD & $4.68 \pm 1.68$ & $5.23 \pm 1.59$ & 0.278 \\
\hline Increased cough, n (\%) & $50(67.6 \%)$ & $3(23.1 \%)$ & 0.003 \\
\hline $\begin{array}{l}\text { Increased sputum volume, } \\
\text { n (\%) }\end{array}$ & $47(63.5 \%)$ & $6(46.2 \%)$ & 0.19 \\
\hline Chest pain, n (\%) & $9(12.2 \%)$ & $2(15.4 \%)$ & 0.517 \\
\hline D Dimer $(\mu \mathrm{g} / \mathrm{mL})$, mean $\pm \mathrm{SD}$ & $1.50 \pm 0.98$ & $2.24 \pm 1.16$ & 0.02 \\
\hline $\mathrm{PaO}_{2} / \mathrm{FiO}_{2}$ ratio, mean $\pm \mathrm{SD}$ & $242.9 \pm 73.9$ & $263.1 \pm 106.9$ & 0.439 \\
\hline $\mathrm{PaCO}_{2}(\mathrm{mmHg})$ mean $\pm \mathrm{SD}$ & $54.53 \pm 20.06$ & $46.72 \pm 14.49$ & 0.183 \\
\hline Lactate $(\mathrm{mmol} / \mathrm{L})$, mean $\pm \mathrm{SD}$ & $1.82 \pm 0.99$ & $1.82 \pm 0.45$ & 0.992 \\
\hline $\mathrm{pH}$, mean $\pm \mathrm{SD}$ & $7.34 \pm 0.99$ & $7.36 \pm 0.83$ & 0.479 \\
\hline $\mathrm{CRP}(\mathrm{mg} / \mathrm{mL})$, mean $\pm \mathrm{SD}$ & $70.87 \pm 74.88$ & $61.38 \pm 97.15$ & 0.688 \\
\hline Troponin $(\mathrm{ng} / \mathrm{mL})$, mean $\pm \mathrm{SD}$ & $0.14 \pm 0.54$ & $0.22 \pm 0.29$ & 0.62 \\
\hline $\mathrm{BNP}(\mathrm{ng} / \mathrm{mL})$, mean $\pm \mathrm{SD}$ & $350.57 \pm 474.27$ & $343.40 \pm 336.98$ & 0.964 \\
\hline
\end{tabular}

$\mathrm{PE}=\mathrm{Pulmonary}$ Embolism. $\mathrm{FEV}_{1}=$ Forced Expiratory Volume in 1 second. $\mathrm{CRP}=\mathrm{C}$ Reactive Protein. BNP=B Natriuretic Protein.

Table 2: Comparisons of anthropometric, clinical, functional and biological data between patients with pulmonary embolism ( $P E$ group, $N=13$ ) and patients without pulmonary embolism (Non PE-group, $\mathrm{N}=74$ ).

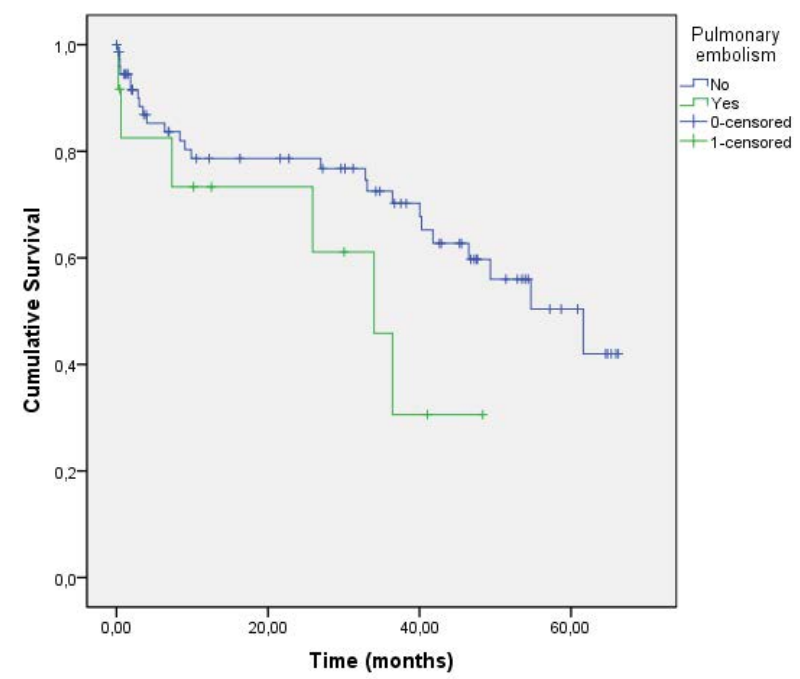

Figure 2: Mortality rates according to the presence or not of a pulmonary embolism.

When considering COPD exacerbation, the prevalence of $\mathrm{PE}$ seems to differ between patients that require hospitalization and those who do not. According to the 2009 meta-analysis [8], the prevalence of $\mathrm{PE}$ in patients with exacerbated COPD ranges from $3.3 \%$ when evaluated in an emergency department [9] to $19-29 \%$ in outpatients and inpatients $[10,11]$ reaching a maximum of $25-29 \%$ in patients requiring hospitalization $[3,12]$. In our study, subgroup analysis shows that VTE tended to be more frequent in COPD patients that required ICU hospitalization compared to those who were hospitalized in the 
pneumology ward (respectively, $20.5 \%$ vs. $9.8 \%$, NS) but this assertion remains to be confirmed regarding the conflicting data recently published on PE prevalence in patients hospitalized in medical centers: $8 \%$ in a Korean population [13] versus $18 \%$ in an Israelite population [14]. These discrepancies suggest that other risk factors than COPD exacerbation by itself or hospitalization-induced immobilization lead to PE such as comorbidities exposing to a supplemental risk of PE (i.e. cardiovascular disease, cancer, etc...).

When comparing our exacerbated COPD patients with wheezing at presentation, cough appeared less frequent with Wells or Geneva clinical scores higher in patients with PE than without PE suggesting that exacerbation in patients without $\mathrm{PE}$ might be related to a viral and/or bacterial bronchitis (Table 2). As Choi et al. [13], we found that increased values of plasma D-dimers $(\geq 500 \mu \mathrm{g} / \mathrm{L})$ was a significant predicting factor of $\mathrm{PE}$ but no correlations were found between unexpected VTE events and the severity of COPD assessed through the GOLD stages. This result invalidated our hypothesis that the most severe COPD patients are more exposed to VTE and that such VTE events could explain in part the increased mortality observed in the literature in patients from GOLD stage 1 to GOLD stage 4 [15-17]. No other difference in VTE risk factors were observed between patients with $\mathrm{PE}$ and without $\mathrm{PE}$ and this negative result is probably due to the high homogeneity of the population studied.

COPD patients exposed to PE events are usually old and obese male patients [18] but no real specific phenotype has been identified. Our results are confident to those of Tillie-Leblond et al. [12] showing that exacerbated COPD with PE had significantly higher clinical scores (Geneva and/or Wells) and D-Dimer values than patients without PE. In this study, previous thromboembolic disease, malignant disease and decreased $\mathrm{PaCO}_{2}$ (of at least $5 \mathrm{mmHg}$ ) were also significantly associated with PE [12]. Hypocapnia, but also hypoxemia, both typically related to $\mathrm{PE}[3,5,12]$, were not observed in our study where blood-gas data were similar between COPD patients with and without PE contrary to our previous study showing significant lower $\mathrm{PaO}_{2}$ values in exacerbated COPD patients with PE [3]. Because $47.1 \%$ of exacerbated COPD patients of the present study were admitted to ICU, the blood gases disorders related to the exacerbation severity could have masked the specific blood gases variations induced by PE. This result is concordant with the Prospective Investigation of Pulmonary Embolism Diagnosis study [10] or in the large study conducted by Schönhofer and Köhler [19] where arterial blood-gas values were similar between PE and nonPE COPD patients admitted to a respiratory ICU without concomitant major comorbidities.

This study had several limitations: this is a single centre study, the sample size is small, spiral CT angiography was not proposed to COPD patients with a non-high clinical probability of PE and a negative $\mathrm{D}$-dimers blood test at presentation and finally patients with exacerbated COPD without wheezing were not included in the study. In this highly selective COPD population, the PE prevalence appeared, at least, three-fold higher than those of incidental PE [20] which is not surprizing as it is well known that COPD is characterized not only by a local pulmonary inflammatory response associated with prolonged exposure to noxious gases like tobacco smoke but also by a chronic low grade systemic inflammatory response.

$\mathrm{PE}$ is an unquestionably important cause of death with a 3-month mortality rate of $15-18 \%$, even with adequate anticoagulant therapy [21]. In COPD patients, the risk of mortality nearly doubles in case of PE [21] and any delay or in the initiation of treatment is known to impair prognosis [22]. However, management using the current standard-of-care (warfarin) is not easy, requiring frequent blood tests, dietary changes and the constant fear of a major bleed if the international normalized ratio is above the target range. Moreover, anticoagulant therapy remains questionable for isolated subsegmental $\mathrm{PE}$, as the risk of a major bleed is greater than for those with recurrent venous thromboembolism (respectively, $5.3 \%$ vs. $0.7 \%$ ) [23]. At this part of the discussion, many questions remain unanswered: should we treat our patients who are hospitalized for unexplained exacerbated COPD if an isolated subsegmental PE is found? Can subsegmental PE induce exacerbation in such patients or is this finding the consequence of the overuse of spiral CT angiography, as recently suggested by Wiener et al. [24]? In our study, we decided to treat with standard anticoagulant therapy all COPD patients with PE whether it was an isolated subsegmental or a bilateral PE. The anticoagulant therapy did not induce any major bleeding and led to significant benefits in terms of 3-month mortality rates. No statistical differences in outcome were found between patients with proximal, segmental or subsegmental $\mathrm{PE}$. The poor long-term prognosis observed in case of PE occurring in exacerbated COPD patients could justify a prolonged anticoagulant therapy even in case of subsegmental PE but this result needs to be confirmed by larger study (too small subgroups for an accurate statistical analysis).

To conclude, a $21.8 \%$ prevalence of thromboembolic disease was found in patients with exacerbated COPD and wheezing at presentation and these unexpected venous thromboembolism events were not correlated to the severity of COPD.

\section{Authors' Contributions}

CP: participated in the coordination of the study, the data collection and analysis; MW participated in the coordination of the study, the data collection and analysis; EH participated in the data collection and analysis; EM participated in the data collection; MA participated in the data collection; MASP participated in the data collection; DB participated in the data collection; CA participated in the design of the study, performed the statistical analysis and helped to draft the manuscript $\mathrm{VJ}$ conceived of the study, carried out its design, participated in its analysis and draft the manuscript.

All authors read and approved the final manuscript.

\section{Acknowledgements}

English language has been checked by "Newmed Publishing services" (France)

\section{References}

1. Sapey E, Stockley RA (2006) COPD exacerbations. 2: aetiology. Thorax 61 250-258.

2. Fraisse F, Holzapfel L, Couland JM, Simonneau G, Bedock B, et al. (2000) Nadroparin in the prevention of deep vein thrombosis in acute decompensated COPD. The Association of Non-University Affiliated Intensive Care Specialist Physicians of France. Am J Respir Crit Care Med 161: 1109-1114.

3. Mispelaere D, Glerant JC, Audebert M, Remond A, Sevestre-Pietri MA et al. (2002) [Pulmonary embolism and sibilant types of chronic obstructive pulmonary disease decompensations]. Rev Mal Respir 19: 415-423.

4. Webster JR Jr, Saadeh GB, Eggum PR, Suker JR (1966) Wheezing due to pulmonary embolism. Treatment with heparin. N Engl J Med 274: 931-933.

5. Wicki J, Perneger TV, Junod AF, Bounameaux H, Perrier A (2001) Assessing clinical probability of pulmonary embolism in the emergency ward: a simple score. Arch Intern Med 161: 92-97.

6. Wells PS, Anderson DR, Rodger M, Ginsberg JS, Kearon C, et al. (2000) Derivation of a simple clinical model to categorize patients' probability of pulmonary embolism: increasing the models utility with the SimpliRED D-dimer. Thromb Haemost 83: 416-420.

7. Mannino DM, Doherty DE, Sonia Buist A (2006) Global Initiative on Obstructive Lung Disease (GOLD) classification of lung disease and mortality: findings from the Atherosclerosis Risk in Communities (ARIC) study. Respir Med 100: 115 122. 
8. Rizkallah J, Man SF, Sin DD (2009) Prevalence of pulmonary embolism in acute exacerbations of COPD: a systematic review and metaanalysis. Chest 135: 786-793.

9. Rutschmann OT, Cornuz J, Poletti PA, Bridevaux PO, Hugli OW, et al. (2007) Should pulmonary embolism be suspected in exacerbation of chronic obstructive pulmonary disease? Thorax 62 : 121-125.

10. Lesser BA, Leeper KV Jr, Stein PD, Saltzman HA, Chen J, et al. (1992) The diagnosis of acute pulmonary embolism in patients with chronic obstructive pulmonary disease. Chest 102: 17-22.

11. Hartmann IJ, Hagen PJ, Melissant CF, Postmus PE, Prins MH (2000) Diagnosing acute pulmonary embolism: effect of chronic obstructive pulmonary disease on the performance of D-dimer testing, ventilation/ perfusion scintigraphy, spiral computed tomographic angiography, and conventional angiography. ANTELOPE Study Group. Advances in New Technologies Evaluating the Localization of Pulmonary Embolism. Am J Respir Crit Care Med 162: 2232-2237.

12. Tillie-Leblond I, Marquette $\mathrm{CH}$, Perez $\mathrm{T}$, Scherpereel $\mathrm{A}$, Zanetti $\mathrm{C}$, et al (2006) Pulmonary embolism in patients with unexplained exacerbation of chronic obstructive pulmonary disease: prevalence and risk factors. Ann Intern Med 144: 390-396.

13. Choi KJ, Cha SI, Shin KM, Lee J, Hwangbo Y, et al. (2013) Prevalence and predictors of pulmonary embolism in Korean patients with exacerbation of chronic obstructive pulmonary disease. Respiration 85: 203-209.

14. Shapira-Rootman M, Beckerman M, Soimu U, Nachtigal A, Zeina AR (2014) The prevalence of pulmonary embolism among patients suffering from acute exacerbations of chronic obstructive pulmonary disease. Emerg Radiol.

15. Hole DJ, Watt GC, Davey-Smith G, Hart CL, Gillis CR, et al. (1996) Impaired lung function and mortality risk in men and women: findings from the Renfrew and Paisley prospective population study. BMJ 313: 711-715.

16. Schünemann HJ, Dorn J, Grant BJ, Winkelstein W Jr, Trevisan M (2000) Pulmonary function is a long-term predictor of mortality in the general population: 29-year follow-up of the Buffalo Health Study. Chest 118: 656664.

17. Mannino DM, Buist AS, Petty TL, Enright PL, Redd SC (2003) Lung function and mortality in the United States: data from the First National Health and Nutrition Examination Survey follow up study. Thorax 58: 388-393.

18. Bertoletti L, Quenet S, Mismetti P, Hernández L, Martín-Villasclaras JJ, et al. (2012) RIETE Investigators. Clinical presentation and outcome of venous thromboembolism in COPD. Eur Respir J 39: 862-868.

19. Schönhofer B, Köhler D (1998) Prevalence of deep-vein thrombosis of the leg in patients with acute exacerbation of chronic obstructive pulmonary disease. Respiration 65: 173-177.

20. Dentali F, Ageno W, Becattini C, Galli L, Gianni M, et al. (2010) Prevalence and clinical history of incidental, asymptomatic pulmonary embolism: a metaanalysis. Thromb Res 125: 518-522.

21. Goldhaber SZ, Visani L, De Rosa M (1999) Acute pulmonary embolism clinical outcomes in the International Cooperative Pulmonary Embolism Registry (ICOPER) Lancet 353: 1386-1389.

22. Hull RD, Raskob GE, Brant RF, Pineo GF, Valentine KA(1997) The importance of initial heparin treatment on long-term clinical outcomes of antithrombotic therapy. The emerging theme of delayed recurrence. Arch Intern Med 157: 2317-2321.

23. Donato AA, Khoche S, Santora J, Wagner B (2010) Clinical outcomes in patients with isolated subsegmental pulmonary emboli diagnosed by multidetector CT pulmonary angiography. Thromb Res 126: 266-270.

24. Wiener RS, Schwartz LM, Woloshin S (2013) When a test is too good: how CT pulmonary angiograms find pulmonary emboli that do not need to be found. BMJ 347: f3368. 